\title{
A CONSTITUIÇÃO DO SUJEITO E SUA HISTÓRIA DE VIDA: AMPLIANDO O OLHAR NA PRÁTICA PSICOPEDAGÓGICA
}

\author{
Ana Celina Aquino Vasconcellos ${ }^{1}$ \\ Instituto Superior de Educação Pró-Saber - ISEPS \\ Cinthia Peixoto Vieira ${ }^{2}$ \\ Instituto Superior de Educação Pró-Saber - ISEPS \\ Danielle Goldsztajn ${ }^{3}$ \\ Instituto Superior de Educação Pró-Saber - ISEPS
}

Meu desejo é o desejo do outro - a partir desse outro que eu passo a ser desejante

\section{RESUMO}

Este artigo tem como objetivo destacar a sessão de anamnese, articulando-a com a metodologia IRDI, idealizada e conduzida pela psicanalista Maria Cristina Kupfer, que apresenta como um dos eixos de sua pesquisa a suposição do sujeito, importante pilar que sustenta a construção da subjetividade da criança. Sabemos que esta etapa dá corpo ao diagnóstico psicopedagógico e nos permite refletir sobre sua história de vida. Como acreditamos ser relevante compreender como a criança se vê e vê o mundo a partir do que se fala sobre e com ela, justifica-se, portanto, a proposta explicitada no título deste trabalho.

Palavras-chave: Ser cognoscente. Eu cognoscente. Sujeito. Subjetividade. Anamnese.

\footnotetext{
${ }^{1}$ Dra. em Educação - USP - Diretora da Clínica social do Instituto Superior de Educação Pró-Saber - ISEPS.

2 Psicopedagoga clínica (CEPERJ e E.Psi.B.A.), terapeuta familiar sistêmica (CEFAI), orientadora profissional (Instituto do Ser), Mestre em Tecnologia (CEFET) e professora e membro da equipe clínica do ISEPS.

${ }^{3}$ Psicopedagoga clínica (CEPERJ) e terapeuta familiar sistêmica (CEFAI), professora e membro da equipe clínica do ISEPS.
} 


\title{
THE CONSTITUTION OF THE SUBJECT AND HIS LIFE STORY: BROADENING THE LOOK IN THE PSYCHOPEDAGOGICAL PRACTICE
}

\begin{abstract}
This article aims to highlight the anamnesis session, articulating it with the IRDI methodology, designe and conducted by psychoanalyst Maria Cristina Kupfer, who presents as one of the axes of her research the supposition of the subject, an important pillar that supports the construction of the child's subjectivity. We know that this stage structures the psychopedagogical diagnosis and allows us to reflect on their life history. As we believe it is relevant to understand how children construct views of themselves and of the world from talks about and with them, the proposal explicit in the title of this work is justified.
\end{abstract}

Keywords: Cognoscent subject. Cognoscent I. Subject. Subjectivity. Anamnesis.

\section{Introdução}

Somos como água, leve e líquida, buscando espaço, em permanente mudança de forma, qualitativamente sofrendo o fluxo. Ensina-nos Bauman (2001) que "o que todas essas características dos fluidos mostram, em linguagem simples, é que os líquidos, diferentemente dos sólidos, não mantêm sua forma com facilidade. Os fluidos, por assim dizer, não fixam o espaço nem prendem o tempo" (p.8). Essa fluidez proposta pelo autor alia-se à fundamentação teórica de Almeida e Silva (1998) que advoga que a Psicopedagogia tem como objeto de estudo o ser cognoscente, um ser pensante, de relação, contextualizado e apaixonado. Um ser pluridimensional que possui três dimensões - uma racional-lógica, uma desiderativa, afetiva, simbólica e uma terceira social, relacional com dois aspectos: contextual e interpessoal - todas constitutivas do processo de construção do entendimento e do conhecimento. Este ser cognoscente está inserido numa dialética de autonomia e determinação. A autonomia do sujeito corresponde à sua ação, isto é, "quanto mais criadora e divergente em relação ao já instituído for essa ação, maior será a autonomia do ser cognoscente" (Almeida e Silva, 1998, p. 31). A dimensão social no seu aspecto interpessoal concebe o ser cognoscente como um ser de relação, determinado pelas inter-relações mediatizadas pela linguagem que ele estabelece com os outros sujeitos.

Já a determinação, ao contrário, está associada à própria dimensão que constitui o sujeito. Assim sendo, a dimensão social é constitutiva do processo na medida em que o ser cognoscente é um ser contextualizado, isto é, determinado pelas condições existentes na sociedade. Para Bourdieu é um ter (capital cultural) que se tornou ser, uma propriedade que se fez corpo e tornou-se parte da 'pessoa', um habitus". (Bourdieu, 2005, p. 74). É o habitus como um sistema que envolve esquemas de percepção, de apreciação e de ação, ou seja, um conjunto de conhecimentos práticos adquiridos ao longo do tempo, que permite perceber e agir num universo social. Para Vasconcellos (2009) corresponderia a uma matriz por meio da qual o indivíduo pensa, vê e age nas mais variadas situações.

Dolle ressalta (In: Almeida e Silva, 1998, p. 42) que o homem é uno e múltiplo, múltiplo estruturalmente e uno na sua multiplicidade, na sua unidade. É uno funcionalmente. É o eu que unifica a diversidade. Uno em sua ação, em sua atividade de conhecer. Para Almeida e Silva (1998) o ser cognoscente é universal, ele é aquele de quem se fala, do qual se fala. Por outro lado, 
o EU cognoscente é quem fala, o sujeito que fala, na singularidade de cada um de nós. Desse mesmo lugar é concebido por Kupfer que "o eu ocupo necessariamente um lugar central, já que ali se encontra a sede de todas as funções responsáveis pela regulação da relação de uma pessoa com a realidade" (2001, p. 25).

Pensando neste ser entrelaçado na lógica, na paixão e na relação, não concebemos mais a cognição baseada somente em fundamentos lógicos. Não se pensa somente racionalmente, pensa-se também simbolicamente e no nível das relações. Por esta razão, colocamos como centro da nossa demanda o sujeito cognoscente (Almeida e Silva,1998).

A partir desse cabedal teórico criou-se o espaço do Centro de Estudos Psicopedagógicos Pró-Saber. Nesse caminhar alcançou a chancela de Instituto Superior de Educação tendo como fundamentação teórica a Psicopedagogia, teoria essa que nos inspira, que norteia a todos nós e a todos os nossos projetos. Dentre os quais a clínica psicopedagógica. Zenícola (2007) postula que

Ao definir-se o 'espaço psicopedagógico', há que ter em conta o ser em processo de construção do conhecimento, um ser racional, afetivo e relacional, bem como o objeto do fazer psicopedagógico. Portanto, considerar o caráter objetivo e o caráter subjetivo contido no ato de aprender e, consequentemente, nas relações que se estabelecem. (p. 183)

\section{Discussão}

O processo clínico de avaliação psicopedagógica é permeado por dois conceitos fundamentais: do ser humano e o de problema de aprendizagem. Assim, as dificuldades de aprendizagem estão ligadas ao homem como um todo e neste sentido "O sintoma emerge de um processo que, como o processo de aprendizagem, [...] coloca em jogo a pessoa total com homogeneidade funcional e heterogeneidade estrutural" (Teixeira e Genescá, 1987). Diz Bleger a esse respeito: "a relação sujeito-meio não é, (...) uma simples relação linear de causa e efeito entre dois objetos distintos e separados e sim que ambos são integrantes de uma só estrutura total, no qual o agente é sempre a totalidade do campo e os efeitos produzem-se também sobre ou dentro dele mesmo, como unidade" (Bleger, 1984, p.37). Logo, na tentativa de descobrir, avaliar e analisar os obstáculos na construção do conhecimento, tomamos o homem total em suas diversas dimensões, focalizando, provisoriamente, cada uma em si para depois integrá-las em uma totalidade.

De acordo com Oliveira e Bossa (2000, p.5), a prática psicopedagógica "é um lugar privilegiado para se observar as relações entre estruturas cognitivas e simbólicas", sendo necessário, para compreender o sujeito (conhecimento/desejo), articular os problemas de aprendizagem com o inconsciente.

Os eixos da Pesquisa IRDI ${ }^{1}$, desenhada e coordenada pela psicanalista Maria Cristina Kupfer estudam o desenvolvimento psíquico infantil desde seu nascimento. Estes eixos nos delineiam um caminho na ideia pensada do conceito lacaniano de suposição de sujeito e que gostaríamos de trazê-lo por considerarmos fundamental na observação no diagnóstico e durante o tratamento na clínica psicopedagógica.

Bem sabemos, e a psicanálise nos ensina, que o surgimento do sujeito se encontra primeiramente no exterior - no Outro. $O$ bebê humano nasce ainda prematuro - e seu universo se organiza pelas significações produzidas pela linguagem - como campo simbólico - na qual a criança 
é introduzida na linguagem e no mundo pelo Outro que exerce as funções parentais: materna e paterna. Esse elemento, a linguagem, é apropriado e introjetado e é o organizador dos aspectos psíquicos desse sujeito em construção, sendo o eixo central na constituição do sujeito psíquico.

A suposição do sujeito é a antecipação realizada pelo agente materno. $O$ bebê não nasce como eu, se constitui sujeito. É uma suposição que permite que as reações do bebê sejam tomadas pela mãe como um apelo. (Kupfer; Bernardino \& Mariotto, 2012, p. 97). Manifesta-se como uma antecipação, realizada pelo adulto de referência (pais, cuidadores, adultos privilegiados nos contatos com a criança), da presença de um sujeito psíquico deste bebê, que ainda não se encontra, porém, constituído. Desse modo, o psiquismo ainda não instalado pode efetivamente construir-se. $\mathrm{O}$ corpo do bebê será marcado não apenas pelos cuidados concretos e a satisfação de suas necessidades, mas também pelas experiências prazerosas que ele extrai nos contatos com os adultos de referência. Os indicadores poderão apontar para a existência de perturbações no desenrolar do diálogo mãe-bebê e podem ser percebidos na entrevista inicial e na anamnese pela maneira que o adulto de referência fala, olha e vê essa criança que traz para o atendimento psicopedagógico. A existência de um sujeito que fala de si no seu sintoma é fundamental para que se dê o encontro do psicopedagogo com o sujeito atendido, tal qual faz o adulto privilegiado na relação com a criança. "Considerar histórias e acontecimentos, bem como a dinâmica familiar [...]" (Goldsztajn, 2018, p. 66) é algo relevante nesse processo.

É neste entrelaçar entre o racional e as pulsões que repousa o objeto deste artigo, a partir da reflexão sobre a importância da condução e do olhar no processo psicopedagógico.

Ao abordar este tema, é necessário que discorramos, ainda que sucintamente, sobre a nossa matriz de pensamento diagnóstica. Da avaliação psicopedagógica fazem parte uma entrevista inicial com os pais e a criança, sessões diagnósticas somente com o cliente, uma ou mais sessões de anamnese com os pais e finalizamos com as sessões de devolução dos resultados.

É pelo viés da criança que realizamos nossa primeira aproximação por ela ser o sujeito desse diagnóstico. Buscamos primeiramente escutá-la a partir do seu lugar para estabelecer uma relação de confiança ao acolher suas ansiedades frente ao novo, para percebê-la na sua vinculação consigo mesma, com a família e com os objetos e conteúdos de aprendizagem escolar, observando suas defesas, suas condutas de fuga ou enfrentamento diante dos desafios. Também buscamos conhecer seu funcionamento e o desenvolvimento de suas funções lógicas, bem como compreender a função do sintoma, seja ele manifesto ou latente. Teixeira e Genescá (in Almeida e Silva, 2006, p. 25) propõem "o sintoma como sinal, produto, emergência de uma desarticulação" das dimensões constitutivas do sujeito. Para Fernández (2010, p. 112)

O sintoma problema de aprendizagem tem uma característica muito particular em relação aos outros sintomas, justamente porque inclui a inteligência. A inteligência é aquela capacidade humana que nos permite enunciar e elaborar a angústia.

Continuando com suas reflexões, Fernández cita:

Como disse Mannoni, 'O sintoma é um grito de denúncia'. Eu digo, a partir de Mannoni, 'O sintoma problema de aprendizagem é um grito de denúncia que renuncia a enunciar o mesmo que denuncia' [...] O dramático desse problema é que, quando denuncia, renuncia a enunciar aquilo que denuncia. (Fernandez, 2010, p.112).

Portanto as dificuldades de aprendizagem estão ligadas ao homem como um todo e, neste sentido, podemos, tal qual Pain (1985), considerar "o problema de aprendizagem como um sintoma, no sentido de que o não-aprender não configura um quadro permanente, mas ingressa numa constelação peculiar de comportamentos, nos quais se destaca como sinal de descompensação" 
(Pain, 1985, p. 28). Para Freud, o sintoma é a solução de compromisso entre o inconsciente e o consciente. A psicopedagoga Almeida e Silva (1998) compreende o sintoma como emergente de uma desarticulação funcional das dimensões racional, desiderativa e relacional. A falsa organização, entre essas dimensões, resulta num problema de aprendizagem que é o sintoma, embora este preserve a organização do Eu cognoscente evitando uma ruptura ou uma mudança. (Vasconcellos, 1992, p. 13). Para nós psicopedagogos, a 'queixa' que a criança, a família e/ou a escola nos apresentam seria como uma "fratura contemporânea de uma série de concomitantes", como argumenta Pain. Não a entendemos "como significante de um estado monolítico e substancial, mas pelo contrário", a consideramos, tal qual Pain "como um estado particular de um sistema que, para equilibrar-se, precisou adotar este tipo de comportamento que mereceria um nome positivo, mas que caracterizamos como não-aprendizagem". Nessa perspectiva "a não-aprendizagem não é o contrário de aprender, já que como sintoma está cumprindo uma função positiva" (Pain, 1985, p, 28), pois é uma forma do sujeito se organizar mesmo que numa falsa organização para lidar com suas questões em busca da compreensão da perturbação da aprendizagem. Portanto, para o psicopedagogo entender o sintoma, significa considerá-lo para além dessa queixa, desse significado que lhe é atribuído e para além dessa demanda. Isso quer dizer que a Psicopedagogia possibilita a esse sujeito "a construção de sua singularidade e a reconstrução de sua história" (Vieira, 2018, p.106) e tem um compromisso que não é com a demanda superficial, não é a demanda do sintoma, mas é a demanda do entendimento, a demanda do próprio sujeito, que é a questão: eu quero entender.

Levando em consideração este Eu cognoscente dentro das suas três dimensões, utilizamos instrumentos que possam delinear quem é este sujeito que está diante de nós, quais são suas habilidades e que fatores podem estar atravessando o percurso de sua aprendizagem, de modo geral. Monte Serrat Barbosa escreve que a

Psicopedagogia é um olhar que tem a intenção de perceber um sujeito que aprende, de forma inteira, em relação com os outros sujeitos, com a cultura, com a história, com os objetos de aprendizagem e com as normas estabelecidas no contexto em que vive. (2007, p. 205).

A sessão de anamnese ${ }^{2}$ é uma entrevista que "deverá ser tão livre quanto possível" (Paín, 2008, p. 42) e tem o intuito de conhecer a história vital da criança. Sendo uma das sessões constitutivas do processo diagnóstico psicopedagógico, ela é realizada depois das sessões nas quais privilegiamos o encontro com a criança. Aprendemos com Visca que por mais que estejamos conscientes de que a neutralidade total seja impossível, acreditamos que essa sequência nos ajuda a ter uma visão inicial "para vê-lo tal como ele é para descobri-lo" (Visca, 1987, p. 70) sem a contaminação de possíveis pré-conceitos e rótulos que podem ser trazidos pelos pais e pela escola. Sendo assim, elegemos o contato e o ato de conhecê-lo como um recorte do seu momento atual sem atravessamentos que seriam possíveis caso ouvíssemos os relatos dos pais a priori. Ao longo da anamnese, o psicopedagogo, além de obter informações sobre o cliente para melhor compreender a problemática trazida no momento da entrevista inicial, proporciona um espaço de escuta, de acolhimento para a família, encurtando o caminho entre a mesma e o terapeuta. Nesta escuta a família tem a oportunidade de fazer um relato da criança em avaliação, evocando fatos e lembranças que vão delineando esse sujeito a partir de sua história pregressa. Vemos neste momento do diagnóstico duas marcas que dão relevância a nossa prática: primeiramente estamos significando o nosso lugar na inter-relação com a família e seus vínculos; os pais ou responsáveis pela criança, contando sobre sua história, fazem "pensável aquilo que aconteceu", incluindo-se na relação vincular de família, pai/mãe/filho, "como sujeitos pensantes" (Fernandez 2010 p. 107) e co-autores da história de seus filhos.

Etimologicamente a palavra anamnese se originou no grego: anamnesis que significa "lembrança, ato de trazer à mente, formada por ANA que significa "para trás", mais a raiz de MIMNEKESTHAI que significa "recordar, fazer lembrar". (site www.origem da palavra.com.br em maio 2017). 
Por meio da conversa com os pais é possível observar, dentre outras coisas, as "modalidades comportamentais" (Paín, 2008, p.41) da família, que podem influenciar o grau de autonomia e o padrão de aprendizagem do filho, bem como encontrar a funcionalidade do sintoma no grupo familiar (Paín, 2008, p. 69).

Para Weiss (2008, p. 63) a anamnese "[...] possibilita a integração das dimensões de passado, presente e futuro do paciente, permitindo perceber a construção ou não de sua própria continuidade e das diferentes gerações, ou seja, é uma anamnese da família [...] que traz em seu bojo seus preconceitos, expectativas, a circulação dos afetos e do conhecimento[...]" (Weiss, 2008, p.63). Ainda de acordo com a autora, é importante a qualidade e como são faladas as coisas e não a quantidade de informações obtidas na anamnese, que "já é, em si, uma intervenção na dinâmica familiar em relação à aprendizagem de vida" (p.65).

A fim de reconstruir a história da criança, começamos nossa anamnese abrindo espaço para os pais ou responsáveis reviverem na memória todos os momentos vivenciados com o bebê. Polity salienta que "a criança vem inscrita no desejo materno (...)" (2004, p. 133). Oliveira e Bossa (2000) trazem a importância do olhar dos pais sobre seus filhos: "É do lugar em que é colocada, que a criança se vê" [...] e "é esse lugar em que se vê que estabelece seus limites e possibilidades" (2000, p.14).

Esta parte da vida de qualquer criança está alocada num tempo em que não guardamos memória consciente, tempo esse denominado por Freud de "período da amnésia infantil" (Freud, 1987), portanto é através do relato dos pais que a criança se apropria desta parte de sua vida. Há atravessamentos de lembranças que, às vezes, parecem não se encaixar no momento que está sendo relatado? Reticente, lacônico, ou com muitos detalhes.... Enfim, é uma tela que vai se permitindo ser pintada e retocada através das diferentes perspectivas e percepções dos responsáveis.

Consideramos importante ouvir os pais sobre as primeiras aprendizagens informais também contempladas na pesquisa IRDI a qual tem como eixos de avaliação psicanalítica: a suposição de sujeito, o estabelecimento da demanda, a alternância presença-ausência e a função paterna complementados nas pesquisas ulteriores $\left(\mathrm{AP}^{3} \mathrm{e} \mathrm{APEGI}^{4}\right.$ ) pelos eixos: o brincar e a fantasia; o corpo e sua imagem; a manifestação diante das normas e posição frente à lei; a fala e a posição na linguagem; a presença e reconhecimento de sujeito e a função de semelhante. Para Kupfer (2008) esses eixos sustentam a construção da subjetividade da criança e Fernandez (2001) considera esses eixos simbólicos na construção da modalidade de aprendizagem. Fernando Pessoa, sob o heterônimo de Álvaro Campos, retrata muito bem a importância desta questão, quando escreve

\section{Sou o intervalo}

entre meu desejo e

aquilo que o desejo

dos outros fizeram

de mim.

(In: Fernández, 2001, p. 89)

Outro ponto abordado nesta conversa diz respeito à amamentação. Aqui nosso interesse está mais no 'como' do que no tempo, propriamente dito, em que a criança foi amamentada. Para nós é importante ouvir como foi essa experiência materna, como era o envolver nos braços e o olhar dessa mãe para o filho neste momento; como foi a participação do pai nessa díade,

Avaliação Psicanalítica aos 3 anos de idade.

Acompanhamento Psicanalítico de crianças em Escolas, Grupos e Instituições (Kupfer, M. C., Bernardino, L. \& Pesaro, M. E.) 
o quanto o pai olhou e envolveu com afeto esse bebê. Seguindo uma linha de tempo, exploramos alguns aspectos que envolvem a passagem do alimento líquido para o semissólido e sólido e sua experimentação sensório-motora, como tocar os alimentos, a coordenação motora, enfim a fase de aprender a comer sozinho. No tocante à aprendizagem do andar, a nossa anamnese gira também na experiência da separação, nos sentimentos que rodearam os pais no momento de deixar que o bebê caminhasse por si só, mesmo sabendo que ele poderia cair e se machucar. A partir do relato dos pais temos uma escuta das primeiras aprendizagens sinalizadas pela apropriação do corpo feita pela criança. Se esse controle se deu precocemente com a entrada na creche ou respeitou-se o intervalo entre o reconhecimento natural do controle dos esfíncteres e $o$ ato de expressar à vontade, seja para a mãe ou para as cuidadoras. Estes indícios nos levam a pensar como esta aprendizagem poderá ser uma marca no seu estilo de apreender o mundo e aprender na escola.

Sendo construtor de seu processo de aprendizagem, leva suas marcas pessoais, as de sua família, do seu meio social e é neste entre que ele cria sua sensibilidade, sua espontaneidade, sua singularidade e seu jeito ímpar de relacionar-se com o mundo e com os objetos formais oferecidos na escola.

Sara Pain (2009) a propósito, considera:

O sujeito não é sujeito até que conheça. É sujeito porque conhece, e é sujeito a esse conhecimento. Um indivíduo recém-nascido, deixado por sua própria conta, não se tornaria um ser humano. Através do conhecimento ele se constitui como ser humano e vai poder se definir como sujeito, como aquele lugar não repetível que cada um considera seu destino. (Pain, 2009, pg. 15).

Por essa razão é importante ouvir sobre como o grupo familiar vive suas próprias aprendizagens e como são vistos seus obstáculos frente à construção do conhecimento. É necessário também compreender qual o lugar da criança na sua família e suas relações com os membros deste grupo. Barone (in Oliveira e Bossa, 2000) reportando-se a importância da aprendizagem na constituição do sujeito humano, diz que "se dá sempre pela intermediação de um outro" (p.62) e vai guardar "os resquícios daquilo que the serviu de base “(p. 63).

A criança, diante das primeiras experiências de aprendizagem escolar, revive, repete e expressa sua maneira pessoal, particular de lidar com a realidade, esta maneira representa uma reedição da história de suas relações passadas. Assim, as experiências de sucesso ou de fracasso nesta aprendizagem [...] vão promover consequências no seu narcisismo. (Barone in Oliveira e Bossa, 2000, p.79).

Alicia Fernández, em seu livro Os idiomas do aprendente (2001), nos leva a refletir sobre a importância da modalidade de aprendizagem familiar e a modalidade ensinante dos pais de uma criança que vem para o atendimento psicopedagógico. Os fatores que estão imbricados na complexidade na qual reside o aprender poderão ser vistos na relação da família com o saber e no modo de circulação do conhecimento neste sistema. Como os pais acolhem, reconhecem e desejam essa criança como aprendente e ensinante? Como lidam com as experiências de satisfação e traumáticas? Há oferecimento de espaços para o brincar, o jogar, para as conversas que valorizam a curiosidade e o poder de escolha da criança? São questões, dentre outras, que norteiam nossa escuta para perceber o vínculo com a aprendizagem não somente no âmbito privado da família como também no espaço público como a escola e a comunidade.

Na relação com o aprender sistemático acreditamos que a figura do ensinante na escola assume papel preponderante na formação da sua identidade. É a forma acolhedora, autorizando, valorizando a criança em sua modalidade de aprender, em suas experiências de criatividade, nas tentativas de acerto, que, junto com a família, vai abrir espaços de autoria e autonomia no pensar e no fazer. Chuster (2004) reflete que 
Escola e família participam do processo de desenvolvimento como matrizes de formação. Constitui-se então um elo entre elas cuja figura de ligação é a criança, o filho, o estudante.

Para que o aluno se torne estudante, é muito importante o sentido que o professor lhe confere para existir como tal e, assim, construir conjuntamente o seu processo do saber formal. (In Polity, 2004, p. 187)

Não podemos deixar de mencionar que as intercorrências tais como a troca constante de escola e falhas na metodologia de ensino, são passíveis de acarretar deficiências que podem criar obstáculos na história escolar de um sujeito.

Polity (2004) aponta para a relevância da comunicação na família e estendemos esta relevância também à qualidade da relação aluno/professor na escola, que terá eco em suas vivências envolvendo a aprendizagem formal. Essas experiências são marcas que carregamos na vida. Citando a autora:

Uma comunicação clara e direta entre os pais e filhos depende de padrões de relacionamento familiar que: valoriza a originalidade; autoriza experiências e descobertas; possibilita a troca do papel de quem ensina e de quem aprende; faça da troca amorosa a tônica do processo ensino-aprendizagem. (Polity: 2004, p. 144-145)

Gostaríamos também de considerar outros pontos que enriquecem o processo diagnóstico psicopedagógico, a saber: pessoas significativas na vida da criança; interesses e habilidades - o que gosta e o que faz bem; saúde - intercorrências infantis e, por fim, a expectativa dos pais pelo processo do diagnóstico.

Entendemos que com o desenvolvimento e crescimento, a criança vai tendo, cada vez mais, a oportunidade de abrir seus horizontes, relacionando-se com um círculo cada vez maior de pessoas. No nosso mundo moderno, é comum que ambos os pais trabalhem e, não são raras as vezes, em que atendemos crianças que são cuidadas pelos avós, por babás ou ficam em creches, quando são pequeninas, ou frequentam escolas em horário integral. É nesses nichos vitais que se situam as pessoas significativas de uma criança. Geralmente são pessoas com as quais a criança cria um vínculo de confiança e sente-se "olhada" e com elas compartilha momentos de satisfação. Todo o relato sobre seu entorno, seja sobre sua família nuclear ou extensa (avós, tios, primos) ou sobre o contexto externo por onde ela transita (creche, escola), nos ajuda a tecer os fios do tapete-história e a fazer um retrato desta criança que estamos atendendo.

Também é reveladora a investigação de eventuais situações negativas vivenciadas pela criança no seio da família, como mortes e separações de pessoas significativas e nascimento de irmãos, e se elas foram passíveis de elaboração. Muitas destas "perdas" podem "embaçar" o desejo e a curiosidade de aprender, de saber, de conhecer.

Quanto aos interesses e habilidades, observamos em algumas famílias a dificuldade que os pais encontram ao se depararem com a pergunta do psicopedagogo: "O que seu filho faz bem?" Eles, por depositarem tantas expectativas na aprendizagem formal, deixam o resto encoberto quando seus filhos os frustram nesta área. Fica sempre uma pergunta no ar: "Será que meu filho não é inteligente?" Françoise Dolto aponta para o fato de que "Todas as crianças são inteligentes. A inteligência escolar não é quase nada diante da inteligência geral. Inteligência é dar um sentido a tudo na vida, não é apenas a escolaridade. (2008, p. 293). Toda criança possui áreas de interesse e se destaca em alguma delas. Acreditamos que a valorização das pequenas conquistas auxilie na superação dos tropeços na aprendizagem e que a nosso ver podem ser momentâneos e passageiros. Entendemos que nesse aprendizado a criança possa se deparar com desafios na área psicossocial, tenha que aprender a lidar com frustrações, a desenvolver resiliência, a fim de tomar consciência de si própria, do seu potencial e dos seus limites. 
Evidentemente que isso tudo ocorre num ser biológico, portanto, levaremos também em conta as informações do seu desenvolvimento corporal e o funcionamento do seu organismo.

Embora necessitemos de dados concretos nesta conversa, para nós é bem claro que

O relato não é neutro, e essa é a maravilha. As pessoas entendem que a objetividade seria a neutralidade. Mas não é assim. Essa é a objetividade dos objetos. A objetividade dos sujeitos não é a neutralidade, é o reconhecimento dessa subjetividade. Essa é a objetividade dos sujeitos. Fazer pensável a intervenção dessa subjetividade. (Fernández, 2010, p. 103)

A procura da família por uma avaliação psicopedagógica, indicada ou não pela escola, é um passo a ser valorizado. Ela pode carregar em si uma carga emocional positiva ou negativa ante ao desconhecido. No primeiro contato telefônico já começa a expectativa sobre o diagnóstico e uma possível leitura de "resolução mágica do problema". Não é só a criança que vem com uma carga de ansiedade para a entrevista inicial, mas também seus pais quando será possível conversar de maneira bastante clara, sobre suas expectativas em relação ao diagnóstico. É nessa entrevista que terão a oportunidade de expressar sentimentos, opiniões, de revelar aspectos familiares, conhecidos ou desconhecidos pela criança, que possibilitam uma melhor compreensão do caso.

\section{Considerações finais}

A família que se predispõe a acolher o sujeito pensante como alguém que sente, age e interage, não somente dentro de padrões pré-estabelecidos por pais que muitas vezes idealizam a figura de seus filhos, vai poder acolher a ideia de cuidar e construir com e não pelos filhos, com equilíbrio, sem descuidos e ao mesmo tempo sem excesso de cuidados, tomando emprestado o conceito winnicottiano - família "suficientemente boa". Cuidar nem sempre nos parece ser tarefa fácil de realizar, pois demanda investimento de tempo, de bom senso e muitas vezes é uma tarefa penosa, pois temos que impor limites e ser firmes e constantes naquilo que determinamos como regras na família, equilibrando a doçura e o afeto com a autoridade que cabe ao papel parental. Leonardo Boff nos chama atenção para o saber cuidar dizendo:

Cabe, portanto, acolher os próprios limites com humildade, sem lamúria. No seu todo, são intransponíveis. Somos seres de incompletude. Não somos Deus. [...]

Há os que têm cuidado em demasia. É a sua exacerbação. A pessoa torna-se obsessiva por se preocupar demasiadamente em cuidar de tudo e de todos. [...]. Assim, também não se pode ser apenas cuidado. Ele é a essência do humano, mas o humano não é só essência. Existe sua história ziguezagueante, as ressonâncias do cuidado, as limitações que cabe acolher e revelar. (1999, p. 159-161)

A tarefa psicopedagógica tem como objetivo tornar este ser pensante, de relação e apaixonado PROTAGONISTA de sua vida, nas palavras de Almeida e Silva, vale dizer, autônomo, atuante, construtor e modificador da sociedade, não apenas figurante ou espectador. Cabe ao psicopedagogo ajudar na construção de autores, atores e não espectadores ou figurantes. Buscamos frestas - nas crianças e jovens que atendemos e mesmo em nós, psicopedagogas - por onde agir, por abrir passagem, para derrubar resistências, para ajudar a compor a sinfonia. Vivemos a fluidez dos líquidos atentas que

[...] tendemos a vê-los (os líquidos) como mais leves, menos 'pesados' que qualquer sólido. Associamos 'leveza' ou 'ausência de peso' à mobilidade e à inconstância: sabemos pela prática que quanto mais leves viajamos, com maior facilidade e rapidez nos movemos (Bauman, 2001, p. 8). 


\section{Referências bibliográficas}

ALMEIDA E SILVA, M. C. Protagonistas do 3o Milênio, palestra proferida no Pró- Saber, outubro 2006.

Em busca de uma fundamentação teórica para a psicopedagogia. Rio de Janeiro: Nova Fronteira, 1998.

BARBOSA, LMS. A Epistemologia da Psicopedagogia: reconhecendo seu fundamento, seu valor social e seu campo de ação. Comemorando os 15 anos da ABPp - Paraná Sul 2006. Ver. Psicopedagogia 2007; 24 (73): 90-100.

BARONE, L. in: OLIVEIRA, V.B.; BOSSA, N.A. Avaliação Psicopedagógica da Criança de Zero a Seis Anos. Petrópolis, RJ: Vozes, 2000.

BAUMAN, Z. Modernidade líquida. RJ: Jorge Zahar, 2001.

BLEGER, Psicologia da conduta. Porto Alegre: Artes Médicas, 1984.

BOFF, L. Saber cuidar: ética do humano - compaixão pela terra. Petrópolis: Vozes, 1999.

BOURDIEU, P. Escritos de Educação. Petrópolis: Vozes [1998]. (Organização de Nogueira, Maria Alice \& Catani, Afrânio), 2005.

CHUSTER in: POLITY, E. (org.) Psicopedagogia: terapia familiar nas dificuldades de aprendizagem. São Paulo: Vetor, 2004.

DOLLE, J.-M. De Freud a Piaget. Lisboa: Moraes Editora, 1979.

DOLTO, F. Quando os filhos precisam dos pais - respostas a consultas de pais com dificuldades na educação dos filhos. São Paulo: Martins Fontes, 2008.

FERNÁNDEZ, A. Os idiomas do aprendente: análise das modalidades ensinantes com famílias, escolas e meios de comunicação. Porto Alegre: Artmed, 2001.

FERNÁNDEZ, A. Psicopedagogia em psicodrama: morando no brincar. Petrópolis: Vozes, 2010.

FREUD, S. (1905). Trois essais sur la théorie de la sexualité. Paris, Gallimard, 1987.

GOLDSZTAJN, D. Uma reflexão sobre a ausência materna nas questões da construção do conhecimento. In: VASCONCELLOS, A. C. A intervenção psicopedagógica: desafios do dia a dia na clínica. Rio de janeiro: Wak Editora, 2018.

KUPFER, M. C. C. \& LERNER, R. Psicanálise com crianças. São Paulo: Escuta, 2008.

KUPFER, M. C., BERNARDINO, L. M., \& PESARO, M. E. (2018). Validação do instrumento "Acompanhamento Psicanalítico de Crianças em Escolas, Grupos e Instituições" (APEGI). Estilos Da Clínica, 23(3), 558-573. https://doi.org/10.11606/issn.1981-1624.v23i3p558-573.

KUPFER, M. Cristina M., BERNARDINO, Leda Mariza Fischer \& MARIOTTO, Rosa M. Marini (orgs.). Psicanálise e ações de prevenção na primeira infância. SP: Escuta/FAPESP, 2012. 
KUPFER, Maria Cristina. Educação para o futuro. Psicanálise e educação. São Paulo: Escuta, 2001, 2a Ed.

OLIVEIRA, V.B.; BOSSA, N.A. Avaliação Psicopedagógica da Criança de Zero a Seis Anos. Petrópolis, RJ: Vozes, 2000.

PAIN, S. Diagnóstico e Tratamento dos Problemas de Aprendizagem. Porto Alegre: Artmed, 1985.

Subjetividade e Objetividade. Relação entre Desejo e Conhecimento. Petrópolis, RJ: Vozes, 2009.

PESSOA, F. in: FERNÁNDEZ, A. Os idiomas do aprendente: análise das modalidades ensinantes com famílias, escolas e meios de comunicação. Porto Alegre: Artmed, 2001.

POLITY, E. (org.) Psicopedagogia: terapia familiar nas dificuldades de aprendizagem. São Paulo: Vetor, 2004.

TEIXEIRA, M. L. E GENESCÁ, A. M. Documento-base do grupo de controle. In MAMEDE NEVER, M. A. C. (coord.). O ensino de matemática e o desenvolvimento das estruturas cognitivas operatórias - uma proposta inovadora. Projeto final PADCT, 1985-1987.

VASCONCELLOS, Ana Celina Junqueira de Aquino Barretto de. A civilização escolar e as camadas populares: a tecitura do cotidiano escolar. 2009. Tese (Doutorado em Educação) - Faculdade de Educação, University of São Paulo, São Paulo, 2009. Disponível em: <http://www.teses. usp.br/teses/disponiveis/48/48134/tde-23092009-140751/>. Acesso em: 2015-02-06

VIEIRA, C. P. Afeto “inteligente": uma proposta para individuação, autoria e autonomia. In: VASCONCELLOS, A. C. A intervenção psicopedagógica: desafios do dia a dia na clínica. Rio de Janeiro: Wak Editora, 2018.

VISCA, J. Clínica psicopedagógica Epistemologia Convergente. Porto Alegre: Artes Médicas, 1987.

WEISS, M.L.L. Psicopedagogia Clínica- uma visão diagnóstica dos problemas de aprendizagem escolar. Rio de Janeiro: Lamparina, 2008.

ZENICOLA, A. M.; BARBOSA, L. M. S.; CARLBERG, S. Psicopedagogia: saberes/olhares/fazeres. São José dos Campos: Pulso, 2007. 